\title{
Correction to: Effects of Temperature Ramping Ageing on Mechanical Properties and Microstructure of Al-4.11Zn-1.77Mg Alloy
}

\author{
F. SHI ${ }^{1}$ C.C. WANG ${ }^{2}$ X.Y. LIU, ${ }^{1}$ X. WANG $10,{ }^{1,6}$ J.C. HUANG ${ }^{3}$ \\ D.M. JIANG, ${ }^{4}$ M. WU, ${ }^{5}$ and Z.C. ZHANG ${ }^{1}$
}

1.-School of Mechanical Engineering, Liaoning Shihua University, Fushun 113001, People's Republic of China. 2.-State Key Laboratory of Rolling and Automation, School of Materials Science and Engineering, Northeastern University, Shenyang 110819, China. 3.-Institute for Advanced Study, Department of Materials Science and Engineering, City University of Hong Kong, Kowloon, Hong Kong. 4.-Department of Material Science and Engineering, Harbin Institute of Technology, Harbin 150001, People's Republic of China. 5.-College of Petroleum Engineering, Liaoning Shihua University, Fushun 113001, People's Republic of China. 6.-e-mail: wangxu@lnpu.edu.cn

\section{Correction to:}

JOM

https://doi.org/10.1007/s11837-018-3170-z

J.C. Huang's name appeared incorrectly on the original version of this article. It appears correctly here. 